\title{
Expression of transcription factor CREB1 in human breast cancer and its correlation with prognosis
}

\author{
ALOK CHHABRA, HERMAN FERNANDO, GARETH WATKINS, ROBERT E. MANSEL and WEN G. JIANG \\ Metastasis and Angiogenesis Research Group, School of Medicine, Cardiff University, Cardiff, UK
}

Received April 23, 2007; Accepted June 15, 2007

\begin{abstract}
It has been suggested that the cAMP responsive element-binding protein (CREB) may act as a transcription regulator of aromatase in breast cancer cells. However, there is little knowledge on the expression of CREB1 in human breast cancer and its clinical significance. The current study investigated the expression pattern of CREB1 in human breast cancer at the mRNA and protein level and correlated it with the clinical outcome. CREB1 staining was primarily seen in the nucleus of both normal and tumour cells. At the mRNA level, we found a significantly higher level of CREB 1 in breast tumour tissues $(n=120)$ as compared to non-neoplastic mammary tissues $(n=33, p=0.0092)$. When compared between different histological types CREB1 expression was significantly higher in ductal carcinoma as compared to lobular and other breast carcinoma. Patients with a poor prognosis and with metastasis had a markedly raised level of CREB1 compared to patients who were disease free. In addition, node-positive tumours had higher levels of CREB1 than node-negative tumours $(\mathrm{p}=0.0018)$. Finally, patients with high levels of CREB1 had a significantly shorter disease-free survival [95.3 (68.4-122.3, 95\% CI) months] compared with those with lower levels [133.9 (123.5-144.2) months, $\mathrm{p}=0.0193]$. This study demonstrates that the level of CREB 1 in breast cancer patients is elevated and is significantly raised in patients with a poor prognosis, metastatic disease and nodal involvement. We conclude that the level of CREB1 expression is aberrant in human breast cancer and is associated with disease progression in breast cancer patients.
\end{abstract}

\section{Introduction}

Breast cancer is a major health problem and is the most frequently occurring cancer in women worldwide. It accounts for approximately $25 \%$ of all female malignancies and the proportion is higher in women in developed countries with

Correspondence to: Dr Alok Chhabra, Department of Surgery, School of Medicine, Cardiff University, Cardiff, CF14 4XN, UK E-mail: chhabraa1@ cardiff.ac.uk

Key words: CREB1, aromatase, breast cancer, transcription factors the incidence rising in many parts of the world including Europe and the USA. Approximately $70 \%$ of all breast cancers are hormone dependent and oestrogen is the primary hormonal factor that stimulates the growth of hormonedependent breast cancer. Pasqualini et al reported that the concentration of oestrogens in breast cancer tissues is greater than in plasma in postmenopausal women (1). Oestrogen biosynthesis from the oestrogen precursor's dihydroepiandrostenedione and testosterone is catalysed by the enzyme aromatase cytochrome $\mathrm{P} 450$ which in turn promotes the proliferation of breast cancer cells.

In humans, aromatase is expressed in various glandular and extra-glandular sites including ovary, breast, placenta, bone and adipose tissue. The expression of aromatase is highly aberrant in human breast cancer. Various studies have demonstrated that expression of both aromatase mRNA and aromatase protein were significantly higher in breast cancer tissues than in normal breast tissue (2-4). Tumour aromatase is thought to stimulate breast cancer growth in both an autocrine and a paracrine manner (5). Aromatase expression is dependent on multiple tissue specific promoters. In breast cancer tissue it is directed mainly by cAMP-stimulated promoters 1.3 (6) and II (7), while in normal breast tissue it is driven by glucocorticoidstimulated promoter $1.4(8)$.

CREB, cAMP responsive element-binding protein, belongs to a subfamily of the leucine zipper with basic domain (bZip) family of transcription factors. CREB refers to proteins that bind to the CAMP responsive element (CRE) on the somatostatin promoter (9). CREB binds the cyclic AMP response element (TGACGTCA) (10) in the presence of cAMP and activates transcription in response to a variety of extracellular signals including neurotransmitters, hormones, membrane depolarization, and growth and neurotrophic factors. There is evidence suggesting that the CREB proteins form selective heterodimers with each other or with other bZip proteins such as the fos and jun family of proteins (11). These heterodimers' formation in general can alter DNA binding specificity and transcriptional activity and hence the gene expression.

cAMP responsive elements (CRE1 and CRE2) are essential for cAMP-induced promoter II activity (12), which requires phosphorylation by cAMP-dependent protein kinase at serine-119 and -133 (13) for interaction with DNA and RNA polymerase II. It has been reported that CREB may act as a positive transcription regulator of aromatase and hence increased expression and oestrogen synthesis in breast cancer 
cells (12). Despite the extensive study of aromatase, little information is available on the expression and role of CREB in human breast cancer. This study was carried out to investigate the expression pattern of CREB1 in a cohort of breast cancer and normal background tissue. We also correlated the level of expression with the prognosis and clinical outcome of the patients.

\section{Materials and methods}

An RNA-extraction kit, RT (reverse transcriptase) kit and Mastermix for routine PCR and quantitative PCR were obtained from AbGene (Surrey, UK). PCR primers were designed using Beacon Designer (Palo Alto, CA, USA) and synthesized by Invitrogen (Paisley, UK). Molecular-biology-grade agarose and DNA ladder were from Invitrogen.

A first-strand cDNA synthesis kit was purchased from Sigma Chemical Ltd. A universal IHC kit was purchased from Vector Laboratories. Low fluorescent 96-well plates were obtained from Abgene and sealing films were from BioRad (Hemel Hempstead, UK).

Sample collection. Breast cancer tissues $(\mathrm{n}=120)$ and background tissue samples (normal breast tissue) $(n=33)$ were collected (with approval from the local ethics committee) immediately after surgery and stored in liquid nitrogen before processing. Patients were routinely followed after surgery and the median follow-up period was 120 months for this study. The histopathological details, tumour grading (modified Bloom and Richardson's grading system), tumour staging (TNM) and the prognostic index for the patients are shown in Table I.

Tissue processing, RNA extraction and reverse transcriptionpolymerase chain reaction. Frozen sections of breast tissue specimens were cut using a cryostat at a thickness of 5-10 $\mu \mathrm{m}$ and stored at $-20^{\circ} \mathrm{C}(14)$. Approximately $15-20$ sections from each breast tissue sample were homogenized using a handheld homogenizer in ice-cold RNA extraction buffer. The purity and the concentration of RNA were determined using agarose gel electrophoresis and a UV spectrophotometer (Wolfe Laboratories, York, UK). Reverse transcription was carried out from $1 \mu \mathrm{g}$ total RNA using an RT kit with an anchored oligo-dT primer according to the manufacturer's instructions. The polymerase chain reaction (PCR) was performed with cDNA, master mix and the respective primers [5'ggggactatga ggagatgat'3 and 5' actgaacctgaccgtacagtggaggtcttgatgtgaat'3] using the following reaction conditions: $5 \mathrm{~min}$ at $95^{\circ} \mathrm{C}, 20 \mathrm{sec}$ at $94^{\circ} \mathrm{C}, 25 \mathrm{sec}$ at $56^{\circ} \mathrm{C}$ and $50 \mathrm{sec}$ at $72^{\circ} \mathrm{C}$ for 36 cycles followed by a final extension phase of $7 \mathrm{~min}$ at $72^{\circ} \mathrm{C}$. B-actin was used as a housekeeping gene and was amplified simultaneously using the following primers 5'gctgatttgatggagttgga 3 ' and 5 'tcagctacttgttcttgagtgaa3'. The PCR products were then separated on a $0.8 \%$ agarose gel, stained using ethidium bromide and visualized under UV light.

Quantitative analysis of CREB1 transcripts. The transcript level of the CREB1 from the above-prepared cDNA was determined using a real-time quantitative PCR, based on the Amplifluor $^{\mathrm{TM}}$ uniprimer technology (Intergen Company,
Table I. Clinical information for breast tumour tissues analysed.

\begin{tabular}{|c|c|}
\hline Characteristic & $\mathrm{n}$ \\
\hline \multicolumn{2}{|l|}{ Tissue type } \\
\hline Background & 33 \\
\hline Tumour & 120 \\
\hline \multicolumn{2}{|l|}{ Grade } \\
\hline 1 & 23 \\
\hline 2 & 41 \\
\hline 3 & 56 \\
\hline \multicolumn{2}{|c|}{ Nottingham prognostic indicator } \\
\hline 1 & 66 \\
\hline 2 & 38 \\
\hline 3 & 16 \\
\hline \multicolumn{2}{|l|}{ Tumour/nodal status } \\
\hline 1 & 69 \\
\hline 2 & 40 \\
\hline 3 & 7 \\
\hline 4 & 4 \\
\hline \multicolumn{2}{|l|}{ Histology } \\
\hline Ductal & 88 \\
\hline Lobular & 14 \\
\hline Other & 18 \\
\hline \multicolumn{2}{|l|}{ Outcome } \\
\hline Disease free & 81 \\
\hline Metastasis & 7 \\
\hline Local recurrence & 5 \\
\hline Died of breast cancer & 20 \\
\hline Died of unrelated cause & 7 \\
\hline
\end{tabular}

Oxford, UK) modified from a previously reported method (14). Specific pairs of PCR primers were designed by the authors using the Beacon Designer software (version 2, Palo Alto, CA, USA) and to one of the primers (routinely the antisense primer in our laboratory), an additional sequence, known as the $Z$ sequence (5'-actgaacctgaccgtaca-3'), which is complementary to the universal $\mathrm{Z}$ probe (15) (Intergen), was added. Cytokeratin-19 (CK19) was used for comparison of cellularity during the analysis and primers for CK19 were 5'caggtccgaggttactgac-3' and 5'-actgaacctgaccgtacacactttctgcc agtgtgtcttc-3' (16).

The reaction was carried out using the following: Hot-start Q-master mix (Abgene), 10 pmol of specific forward primer, $10 \mathrm{pmol}$ of reverse primer which has the $\mathrm{Z}$ sequence, $100 \mathrm{pmol}$ of 6-carboxyfluorescein (FAM)-tagged probe (Intergen), and cDNA from approximately 50 ng RNA (calculated from the starting RNA in the reverse transcriptase reaction). The reaction was carried out using IcyclerIQ ${ }^{\mathrm{TM}}$ (BioRad) which is equipped with an optic unit that allows real-time detection of 96 reactions, using the following conditions: $94^{\circ} \mathrm{C}$ for $120 \mathrm{~min}$, 


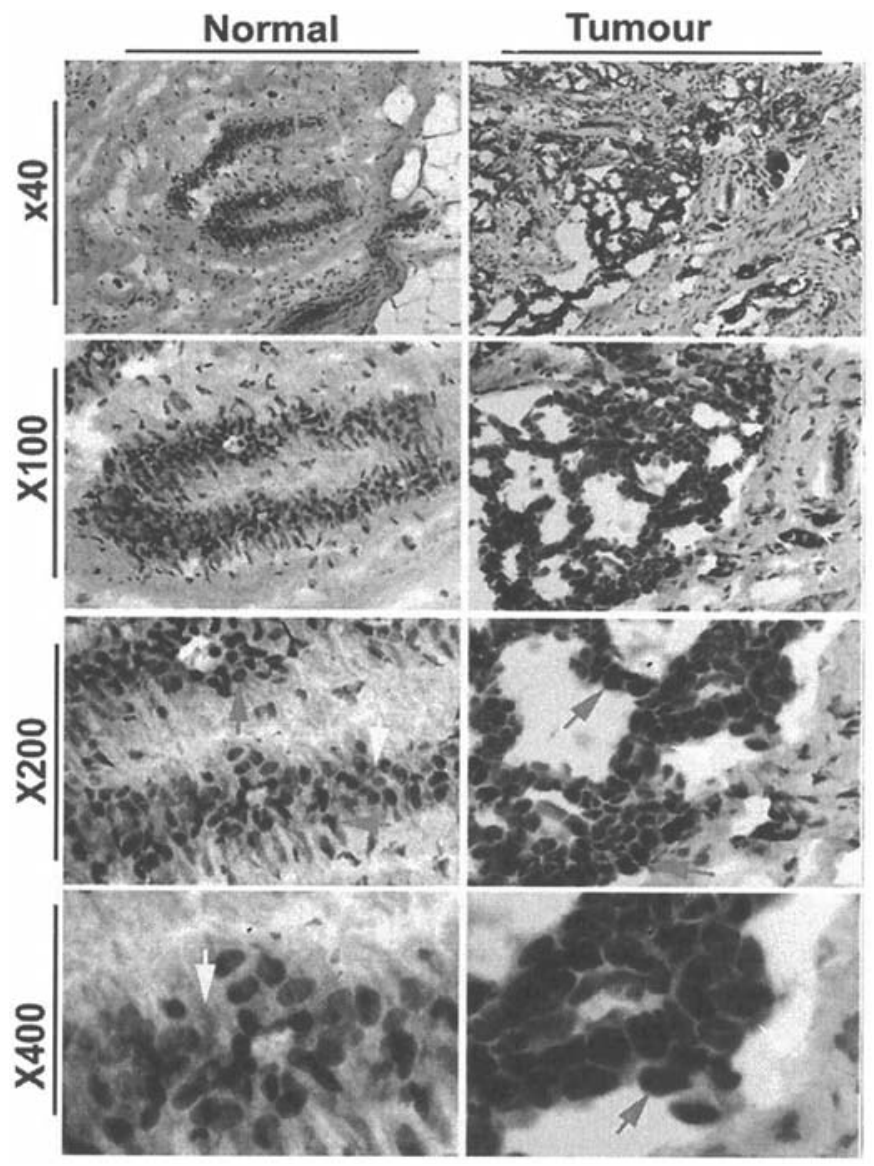

Figure 1. Immunohistochemical staining of normal mammary tissue and breast cancer tissue for CREB1.

50 cycles of $94^{\circ} \mathrm{C}$ for $150 \mathrm{sec}, 55^{\circ} \mathrm{C}$ for $400 \mathrm{sec}$ and $72^{\circ} \mathrm{C}$ for $200 \mathrm{sec}$ (14). The levels of the transcripts were generated from an internal standard that was simultaneously amplified with the samples, and are shown here in two ways: levels of transcripts based on equal amounts of RNA, and as a target/ CK19 ratio.

Immunohistochemical staining of the CREBI proteins. Immunohistochemical staining was carried out using frozen sections of breast tumour and normal mammary tissue cut at a thickness of $6 \mu \mathrm{m}$ using a cryostat. The sections were mounted on Super Frost Plus microscopic slides and air-dried for 20-30 min. The fixed tissue sections were treated in 50\% methanol and $50 \%$ acetone for $15 \mathrm{~min}$. The sections were then air dried for $10 \mathrm{~min}$ and stored at $-20^{\circ} \mathrm{C}$ (wrapped in foil) for further use or immediately stained. The air dried sections were placed in PBS (Optimax wash buffer) for 5 min to rehydrate. The sections were treated with the primary antibodies at specific dilution and incubated for $1 \mathrm{~h}$. The slides were subjected to 4 washes with PBS and then treated in universal multi-link biotinylated secondary antibody at a specific concentration. The slides were incubated for $30 \mathrm{~min}$ followed by 4 washes with PBS and then placed in avidin biotin complex (ABC, Vector Labs). Diaminobenzidine tetrahydrochloride [3,3-diaminobenzidine (DAB)] (Sigma) was added for 5 min to detect the bound antibody. DAB is a substrate for peroxidase and in the presence of $\mathrm{H}_{2} \mathrm{O}_{2}$ a brown precipitate is formed indicating the presence of a specific protein when used in conjunction with specific antibodies. The slides were washed with water for $5 \mathrm{~min}$ and treated in Mayer's haematoxylin for $1 \mathrm{~min}$ followed by a further wash with water for $10 \mathrm{~min}$ (nuclei become blue). The slides were then treated with methanol ( 3 times) and clearing in 2 changes of xyline before mounting under a cover slip. Negative controls (an irrelevant antibody instead of the primary antibody or PBS buffer) were used in this study. The concentrations of antibodies were different to each staining. Cytoplasmic staining of the respective proteins was quantified using Optimas 6.0 software as we described previously (17).

Statistical analysis was carried out using Mann-Whitney U test, the Kruskal-Wallis test and survival analysis using KaplanMeier survival curves and Univariate analysis (SPSS11)

\section{Results}

Distribution pattern of CREB1 in mammary epithelial cells and breast cancer cells. We examined the presence of CREB1 in mammary tissue using immunohistochemical staining. CREB1 staining was primarily seen in the nucleus of both normal and tumour cells. The staining pattern of CREB1 in tumour tissue and in normal mammary tissue was then compared. As shown in Fig. 1 the nucleus staining in normal mammary tissue was weaker as compared with the tumour tissue.

Expression of CREB1 in normal mammary and breast cancer tissues. We analysed the expression pattern of CREB1 in both normal mammary and tumour tissues. As shown in Fig. 2A breast tumour tissues had a higher level of CREB1 as compared to normal breast tissues $(12.5 \pm 1.82$ and $3.7 \pm 1.35, \mathrm{p}=0.0092)$. When compared between different histological types CREB1 expression was significantly higher in ductal carcinoma $(15.4 \pm 2.2)$ as compared to lobular $(6.7 \pm 0.96)$ and other breast

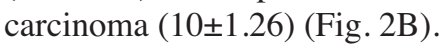

Expression of CREB1 and its correlation with nodal involvement and tumour differentiation. As shown in Fig. 3A, grade-2 $(19.3 \pm 3.6, \mathrm{p}=0.075)$ and grade-3 $(7.9 \pm 2.5, \mathrm{p}=0.1131)$ carcinomas had higher levels of CREB1 expression as compared to grade-1 $(3.4 \pm 3.7)$ carcinoma but they were not statistically significant.

As shown in Fig. 3B, there was a significantly higher level of the CREB1 transcript in node-positive tumours as compared to node-negative tumours $(6.2 \pm 1.8$ in node-negative tumours and $26.5 \pm 3$ in node-positive tumours, $\mathrm{p}=0.0018$ ). The same trend was seen when the CREB 1 transcript was normalized by CK19 (Fig. 3B insert, $\mathrm{p}=0.0004$ ).

Tumours from patients with aggressive disease had higher levels of the CREB1 transcript. Nottingham prognostic index was used as a tool to determine the prognosis of the patients. $\mathrm{NPI}<3.4$ was regarded as having a good prognosis (NPI-1), 3.3-5.4 was moderate (NPI-2) and $>5.4$ indicated a poor prognosis (NPI-3). As shown in Fig. 4A, there was a significantly higher level of CREB1 transcript in patients with a moderate $(30.8 \pm 4.1, \mathrm{p}=0.0036)$ and poor prognosis $(13.2 \pm 2.2$, $\mathrm{p}=0.0061$ ) as compared to patients with a good prognosis 

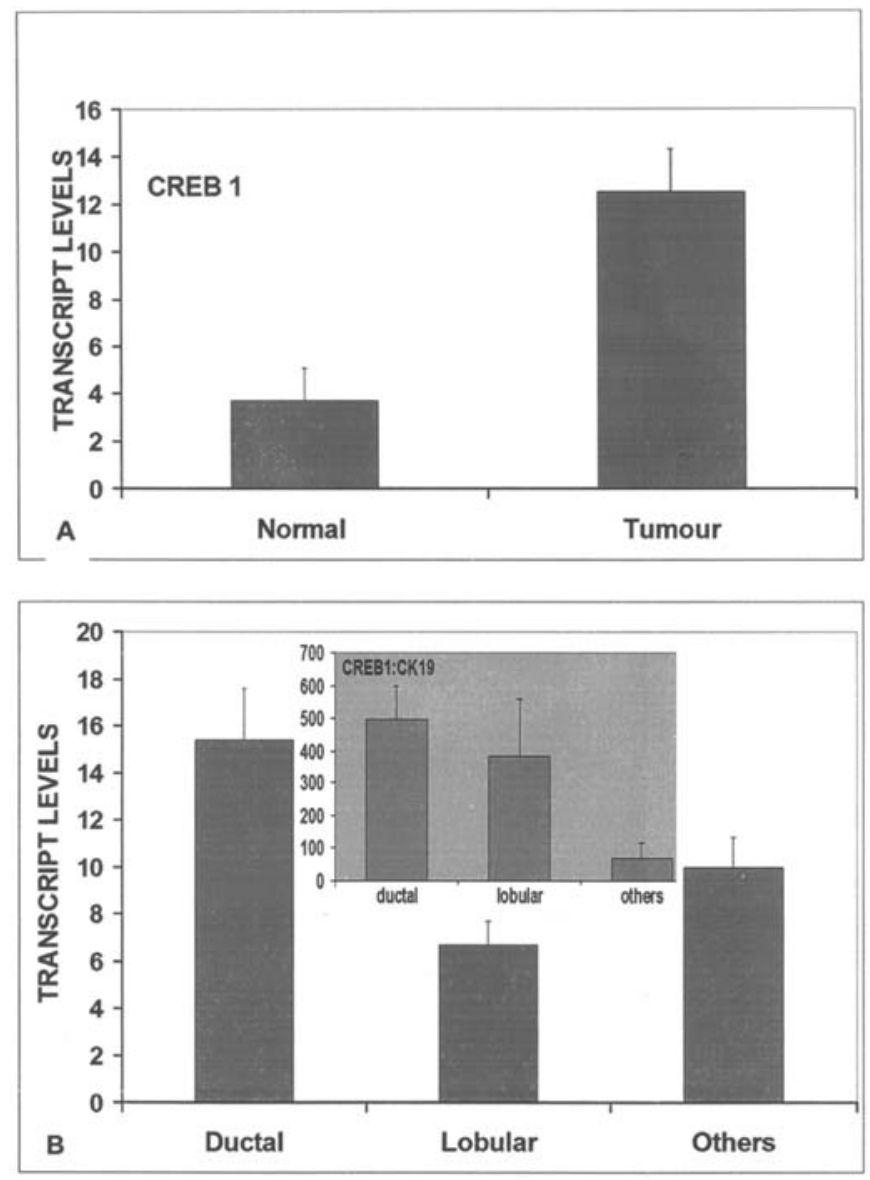

Figure 2. (A) Quantitative real-time PCR demonstrating high expression of CREB1 in tumour samples as compared to normal mammary tissue. (B) Levels of CREB1 transcript levels and its relationship with histological type. Insert: transcript normalised by CK19 (shown as CREB1:CK19 ratio).

(6.2 \pm 1.8$)$. The same trend was seen when the CREB1 transcript was normalized by CK19 (Fig. 4A insert).

High levels of the CREB1 transcript were linked to both the overall and disease-free survival of the patients. Following a median 120-month follow up, patients were divided into the following groups: those who remained disease free, those who developed metastasis or local recurrence and those who died of breast cancer-related disease (excluding non-cancer-related deaths). As shown in Fig. 4B, the CREB1 level was high in patients who developed metastasis $(41 \pm 4.6)$ and who died of breast cancer-related causes $(24.2 \pm 5.2)$ as compared to patients who remained disease free $(8.9 \pm 2.3)$ but it was not statistically significant. Interestingly, when normalised by CK19 a significant difference was seen in tumours from patients who died of breast cancer $(\mathrm{p}=0.0003)$. We combined the three groups (with metastasis, recurrence and mortality), to form a poor prognosis group (Fig. 5A) and compared this group with those who remained disease free. It was demonstrated that the CREB1 level was higher in patients with a poor prognosis (26.5 \pm 3 ) but was statistically not significant. When normalised with CK19 a highly significant difference was seen in patients with a poor prognosis $(\mathrm{p}=0.0035)$.

We have divided patients into groups with high levels of CREB1, by using the NPI as a general guide. When the level
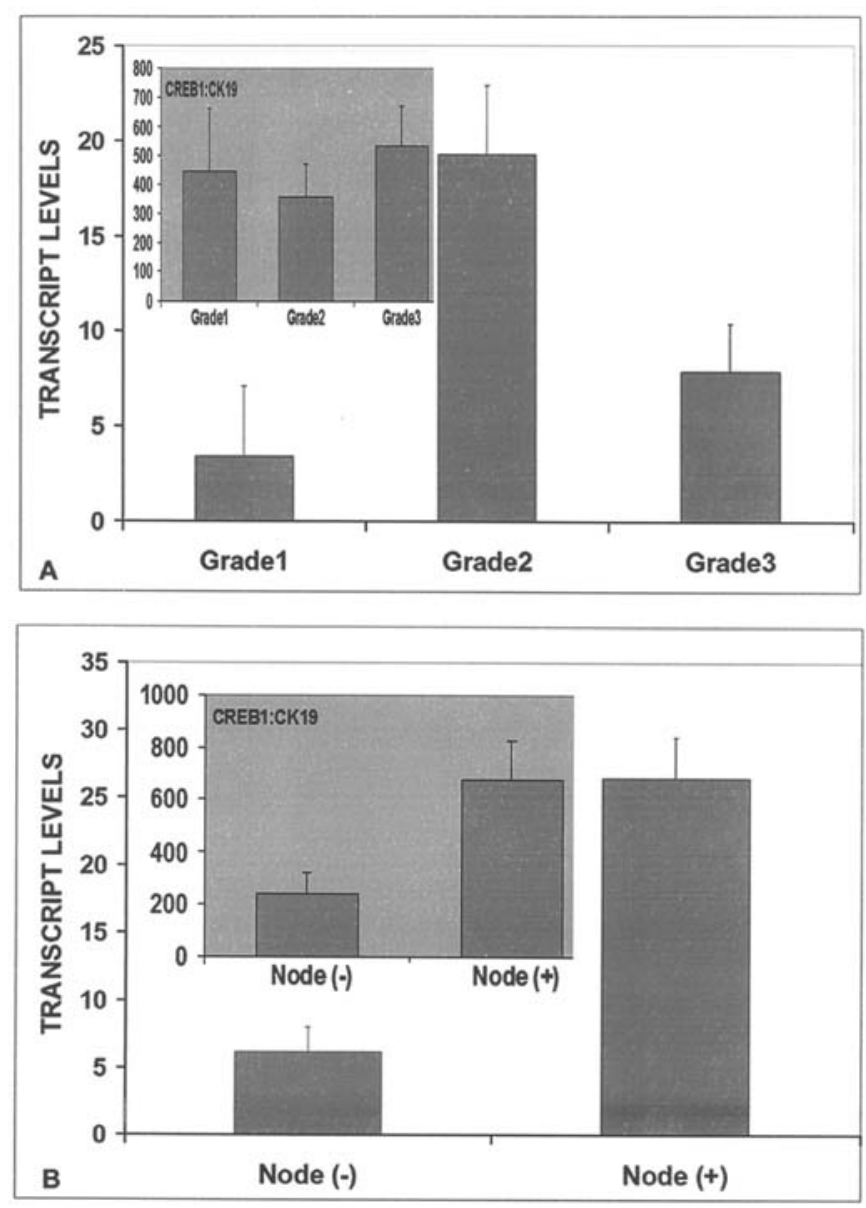

Figure 3. (A) Level of CREB1 and its relationship with tumour grade. Insert: transcript normalised by CK19 (shown as CREB-1:CK19 ratio). (B) RT-PCR analysis of breast cancer tissue samples, showing higher transcript levels of CREB1 in node-positive tumours as compared to node-negative tumours. Insert: transcript normalised by CK19 (shown as CREB1:CK19 ratio).

of CREB1 transcript in a tumour was higher than the tumour with NPI-2 (3.4-5.4, moderate prognosis group), the tumour was arbitrarily regarded as having a high level. When longterm survival was analysed using the Kaplan-Meier survival method, patients with high levels of CREB1 had a significantly shorter disease-free survival [95.3 (68.4-122.3) months] compared with those with lower levels [133.9 (123.5-144.2) months], $\mathrm{p}=0.0193$ (Fig. 5B).

\section{Discussion}

Aberrant transcriptional activity and expression of CREB in cancer cells and clinical tumours has long been recognised. This molecule has been extensively studied in relation to stress response (18), memory (19) and in solid tumours, both benign and malignant $(20,21)$. This protein behaves as both negative and positive regulatory proteins in different solid tumours. Chen et al reported that in cancer tissue increased levels of positive regulatory proteins such as ERR $\alpha-1$ and CREB1 are present as compared to negative regulatory proteins such as EAR-2, COUP-TFI, Snail and Slug (8). Coxon et al have shown a link between an oncogenic chromosomal translocation and CREB activation in malignant salivary gland 

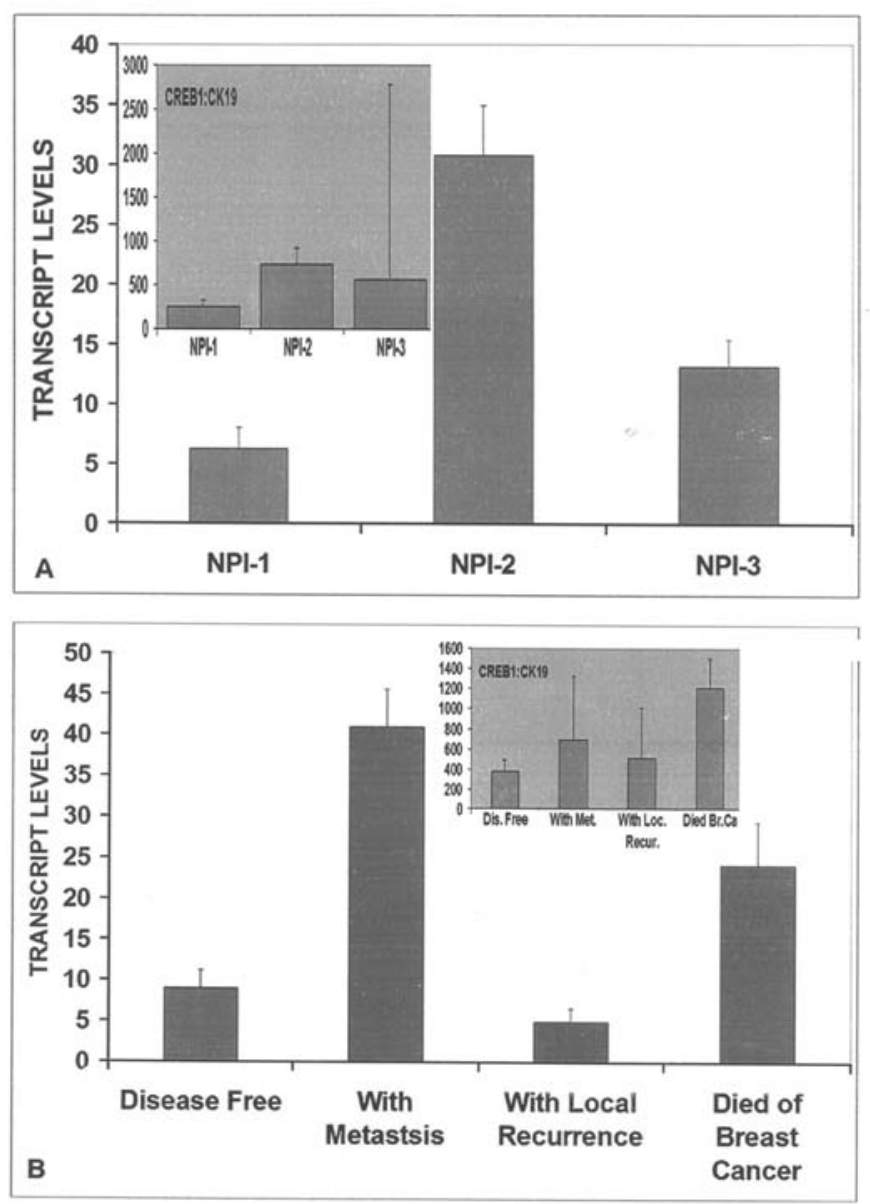

Figure 4. (A) CREB1 and predicted clinical outcome, using the Nottingham Prognostic Index (NPI) as an indicator, in the good prognosis group were patients with NPI<3.4; moderate, with NPI 3.4-5.4; and poor, with NPI $>5.4$. Insert: transcript normalised by CK19 (shown as CREB1:CK19 ratio). (B) CREB1 transcript levels and clinical outcome (median follow-up 120 months). Insert: transcript normalised by CK19 (shown as CREB1:CK19 ratio).

tumours (22). Sofi et al reported that the expression of CREB in tumour bearing breast adipose tissue is higher than in normal breast adipose tissue (12). CREB has an antimitogenic role in solid tumours such as in glioblastoma proliferation (20) and decreased expression is seen in thyroid carcinoma (21).

This study has found that CREB is expressed in both tumour tissue and normal breast adipose tissue with higher levels in tumour tissue. CREB was shown to be predominantly a nucleus protein which was highly stained in breast cancer cell nucleus compared with normal epithelial cells.

The current study reported for the first time that CREB1 is aberrantly expressed in human breast cancer at both protein and mRNA levels and has significant bearing to the clinical outcome of the patients. We assessed the CREB1 level in breast cancer tissue samples against the known prognostic factors and found significantly raised levels of CREB1 in patients with poor prognosis, metastatic disease and nodal involvement. The study has revealed a significant link between CREB and mortality, in that high levels are associated with shorter disease-free survival.

The role of CREB in relation to aromatase expression is still unclear. Overexpression of aromatase in adipose tissue
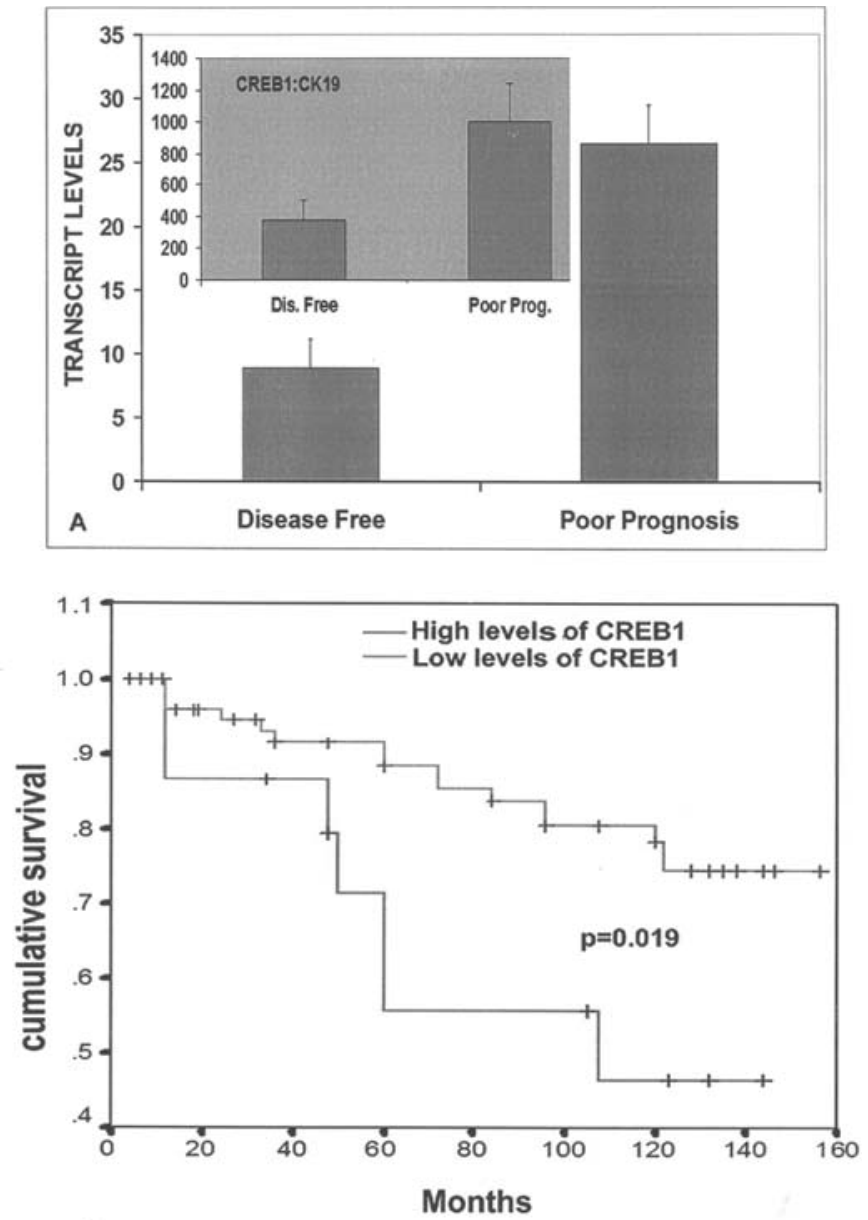

B

Figure 5. (A) Comparison between patients who remained disease free and who had disease progression (recurrence, metastasis and mortality). Insert: transcript normalised by CK19 (shown as CREB1:CK19 ratio). (B) KaplanMeier survival analysis showing correlation between CREB1 transcript levels and the disease-free survival. Patients with high levels of CREB1 had a significantly shorter disease-free survival [95.3 (68.4-122.3, 95\% CI) months] compared with those with lower levels [133.9 (123.5-144.2) months], $\mathrm{p}=0.0193$.

surrounding breast tumour could arise through an increase in both CREB expression and CREB transcriptional activity. Sofi et al reported an increased aromatase expression due to an increase in CREB-induced promoter II activity in tumour bearing breast adipose tissue (12). Further studies needs to be performed to ascertain whether increased expression of CREB leads to aberrant aromatase expression and whether there is a simultaneous decrease in the expression of negative regulatory proteins such as Snail and Slug in breast cancer tissue.

Aromatase inhibitors have been extensively used in the treatment of advanced breast cancer, both in the adjuvant and in the neo-adjuvant setting and are shown to be superior to the ER antagonist (23). Inhibition of CREB activity could inhibit aromatase expression and hence decrease oestrogen production in breast tissue. Therefore overexpression of CREB, together with aromatase in breast cancer tissue at both transcriptional and translational levels may provide a link between CREB pathways and breast tumourigenesis and in future may help in the design of an anti-CREB therapy based on inhibiting aromatase expression as a treatment strategy for breast cancer patients. 


\section{References}

1. Pasqualini JR, Chetrite G, Blacker C, Feinstein MC, Delalonde L, Talbi $\mathrm{M}$ and Maloche $\mathrm{C}$ : Concentrations of estrone, estradiol, and estrone sulfate and evaluation of sulfatase and aromatase activities in pre- and postmenopausal breast cancer patients. J Clin Endocrinol Metab 81: 1460-1464, 1996.

2. Esteban JM, Warsi Z, Haniu M, Hall P, Shively JE and Chen S: Detection of intratumoral aromatase in breast carcinomas. An immunohistochemical study with clinicopathologic correlation. Am J Pathol 140: 337-343, 1992.

3. Santen RJ, Martel J, Hoagland M, Naftolin F, Roa L, Harada N, et al: Stromal spindle cells contain aromatase in human breast tumors. J Clin Endocrinol Metab 79: 627-632, 1994.

4. James VH, McNeill JM, Lai LC, Newton CJ, Ghilchik MW and Reed MJ: Aromatase activity in normal breast and breast tumor tissues: in vivo and in vitro studies. Steroids 50: 269-279, 1987.

5. Sun XZ, Zhou D and Chen S: Autocrine and paracrine actions of breast tumor aromatase. A three-dimensional cell culture study involving aromatase transfected MCF-7 and T-47D cells. J Steroid Biochem Mol Biol 63: 29-36, 1997.

6. Zhou D and Chen S: Identification and characterization of a cAMP-responsive element in the region upstream from promoter 1.3 of the human aromatase gene. Arch Biochem Biophys 371: 179-190, 1999 .

7. Zhou C, Zhou D, Esteban J, Murai J, Siiteri PK, Wilczynski S, et al: Aromatase gene expression and its exon I usage in human breast tumors. Detection of aromatase messenger RNA by reverse transcription-polymerase chain reaction. J Steroid Biochem Mol Biol 59: 163-171, 1996.

8. Chen S, Itoh T, Wu K, Zhou D and Yang C: Transcriptional regulation of aromatase expression in human breast tissue. $\mathrm{J}$ Steroid Biochem Mol Biol 83: 93-99, 2002.

9. Montminy MR and Bilezikjian LM: Binding of a nuclear protein to the cyclic-AMP response element of the somatostatin gene. Nature 328: 175-178, 1987.

10. Deutsch PJ, Hoeffler JP, Jameson JL, Lin JC and Habener JF: Structural determinants for transcriptional activation by cAMP-responsive DNA elements. Biol Chem 263: 18466-18472, 1988.

11. Chinenov Y and Kerppola TK: Close encounters of many kinds: Fos-Jun interactions that mediate transcription regulatory specificity. Oncogene 20: 2438-2452, 2001.
12. Sofi M, Young MJ, Papamakarios T, Simpson ER and Clyne CD Role of CRE-binding protein (CREB) in aromatase expression in breast adipose. Breast Cancer Res Treat 79: 399-407, 2003.

13. Johannessen M, Delghandi MP and Moens U: What turns CREB on? Cell Signal 16: 1211-1227, 2004.

14. Jiang WG, Watkins G, Fodstad O, Douglas-Jones A, Mokbel K and Mansel RE: Differential expression of the CCN family members Cyr61, CTGF and Nov in human breast cancer. Endocr Relat Cancer 11: 781-791, 2003.

15. Nazarenko IA, Bhatnagar SK and Hohman RJ: A closed tube format for amplification and detection of DNA based on energy transfer. Nucleic Acids Res 25: 2516-2521, 1997.

16. King JA, Ofori-Acquah SF, Stevens T, Al-Mehdi AB, Fodstad O and Jiang WG: Activated leukocyte cell adhesion molecule in breast cancer: prognostic indicator. Breast Cancer Res Treat 6: 478-487, 2004.

17. Davies G, Jiang WG and Mason MD: Cell-cell adhesion molecules and signaling intermediates and their role in the invasive potential of prostate cancer cells. J Urol 163: 985-992, 2000.

18. Sabban EL, Liu X, Serova L, Gueorguiev V and Kvetnansky R: Stress triggered changes in gene expression in adrenal medulla: Transcriptional responses to acute and chronic stress. Cell Mol Neurobiol 26: 845-856, 2006.

19. Wagatsuma A, Azami S, Sakura M, Hatakeyama D, Aonuma $H$ and Ito E: De novo synthesis of CREB in a presynaptic neuron is required for synaptic enhancement involved in memory consolidation. J Neurosci Res 84: 954-960, 2006.

20. Perry C, Sklan EH and Soreq H: CREB regulates AChE-Rinduced proliferation of human glioblastoma cells. Neoplasia 6: 279-286, 2004.

21. Luciani P, Buci L, Conforti B, Tonacchera M, Agretti P, Elisei R, et al: Expression of cAMP response element-binding protein and sodium iodide symporter in benign non-functioning and malignant thyroid tumours. Eur J Endocrinol 148: 579-586, 2003.

22. Coxon A, Rozenblum E, Park YS, Joshi N, Tsurutani J, Dennis PA, et al: Mect1-Maml2 fusion oncogene linked to the aberrant activation of cyclic AMP/CREB regulated genes. Cancer Res 65: 7137-7144, 2005.

23. Mauri D, Pavlidis N, Polyzos NP and Ioannidis JP: Survival with aromatase inhibitors and inactivators versus standard hormonal therapy in advanced breast cancer: meta-analysis. J Natl Cancer Inst 98: 1285-1291, 2006. 